\title{
EXPERIENCE OF FEMALE UROGENITAL FISTULA - A SHIFT OF DOMINANCE FROM OBSTETRIC VARIETY TO IATROGENIC ONE
}

\author{
MD. S ISLAM ${ }^{1}$, MD. ZAMAN MASUD ${ }^{1}$
}

\begin{abstract}
Aim: This retrospective study was carried out in Jessore Medical College Hospital and Jhenidah District Hospital on different types of female urogenital fistulae to evaluate its aetiological aspect in the present health care scenario of the country.

Materials and Methods: Female patients presenting with features of urogenital fistula were evaluated properly and operated through intra-abdominal and vaginal route depending upon the merit of the fistula. Aetiological pattern of the cases was evaluated along with surgical outcome and post-operative complications.

Result: Ofthe 28 female urogenital fistulas, 27 (96.43\%) were VVF and 1(3.57\%) was UVF. Out of 28 cases, $71.42 \%$ (20patients) were post-hysterectomy complication, 21.42 $\%$ ( 6 patients) cases resulted from birth trauma and $7.14 \%(n=2)$ cases were post caesarean complication. Trans-abdominal route was used for operation in 22 (78.56\%) cases while $6(21.42 \%)$ cases were operated through trans-vaginal route. In this series of 28 cases, $89.29 \%$ ( 25 cases) patients were fully cured and $10.71 \%$ (3cases) patients experienced recurrence.

Conclusion: The aetiological pattern of the female urogenital fistula in our country has changed substantially from the dominance of birth trauma to post hysterectomy indicating a remarkable improvement in maternal care system along with development of other socioeconomic parameters.
\end{abstract}

Bangladesh J. Urol. 2018; 21(2): 71-75

\section{Introduction}

Childbirth is a normal physiological process required for the continuation species. But before the advent of modern medical care this normal physiological phenomenon would pose the young femalesto number of child birth injuries of which the urogenital fistula was the most devastating one[5]. These young females, incontinent of urine, ashamed of the rank of personal offensiveness, abandoned by their husbands, outcast of the society, and unemployable except in the field would live and exist without hope and without friend. Since the middle of nineteenth century development of medical science has eliminated this dehumanizing curse from the western European countries and the USA and caused its prevalence to fall precipitously in

1. Assistant Professor, Department of Urology, Jessore Medical College, Jessore, Bangladesh.

Correspondences: Islam MS, Assistant Professor, Department of Urology, Jessore Medical College, Jessore, Bangladesh.

Received: 9 August 2017

Accepted: 05 March 2018 the more industrialized nations of the Asia and Latin America. The havoc of this horror is still present in the third world countries where access of the pregnant women to the efficient and effective emergency obstetric care isyet to be developed[5]. The prevalence of obstetric urogenital fistula actually reflects the quality of maternal care provided to the pregnant women in a society.

Hence the incidence of maternal mortality and thatof obstetric[5] urogenital fistula reveals the same status[5] of the health caresystem of a particular society[5]. The countries where obstetric urogenital fistula has vanished have improved their maternalhealth caresystem significantly along with other ${ }^{6}$ areas of development[5]. The causes of urogenital fistula in the developed nations are post-surgical, post radiation and malignancy. In Bangladesh the aetiological pattern of female urogenital fistula has changed too reflecting the development of improved maternal health. 


\section{Method and materials}

This retrospective study was carried out during the period extending from January,2010 to December,2015 in a district hospital and a medical college hospital on the female patients operated for different kinds of urogenital fistulae to evaluate the its aetiological aspect in the present health care scenario of the country. Patients presenting with features suggesting urogenital fistulae were evaluated with proper history, meticulous physical examinations and relevant investigations including the followings-

Vaginal speculum examination with adequate light. Urine $-R / E$ \& $C / S$

S. creatinine

IVU

Urethrocystoscopy

Other investigations for anaesthesia.

Urinary infection if detected with urinalysis was treated with appropriate antibiotic. Surgical repair was not attempted before the lapse of at least 4 months after the onset of fistula.VVF located in the vaginal vault and UVF were repaired through abdominal approach.Low VVF was repaired through vaginal approach.

\section{Abdominal approach}

The previous abdominal incision was used for entry into abdomen. Urinary bladder was bi-valved up to the fistulous opening and ureteric orifices were cannulated with $5 \mathrm{Fr}$ feeding tube. Incision was made around fistula from the bladder end and the tract was completely excised until healthy well vascularized marginappeared. Bladder was closed in layers in imbricated[5] fashion with $3 / 0$ vicryl. Vaginal opening was closed with $1 / 0$ vicryl. Inter-positionalomental flap was used between bladder and vagina[5]. Indwelling urethral catheter was left for 3 weeks.

Ureteroneocystomy was done in patients with ureterovaginal fistulae.

\section{Vaginal approach of repair}

Under anesthesia the patient was placed in lithotomy position. Exposure was maintained with vaginal speculum and labial retraction sutures. Cystoscopy was performed for the reassessment of fistula. Following urethral catheterization a 8-10 FrFoley catheter was introduced through fistula to maintain traction during dissection. Saline was injected around the fistulous track and proposed incision line on the anterior vaginal wall. U- Shaped incision was made on the anterior vaginal wall after having circumscribed the fistulous opening. Vaginal flaps were developed $2-4 \mathrm{~cm}$ away from the fistulous opening. Bladder opening was closed in two layers invaginating the first with the second one. Martius flap was developed from the labia majora and interposed between vagina and bladder.Vaginal flaps were advanced and closed beyond bladder closure. An indwelling Foley urethral catheter was left for three weeks with anti-cholinergic agents added.

\section{Results}

Table I

Basic facts of the fistula patient.

\begin{tabular}{lll}
\hline Character & Range & Mean \\
\hline Age & $17-53$ years & 35.37 years \\
Time lapse between onset and repair & 4 months -29years & 10.27 months \\
Operative time & 45 minute- 1.80 hours & 1.3 hours. \\
Hospital stay & 5 days-8days & 6.5 days \\
\hline
\end{tabular}

Table II

Incidence of different type of fistula.

\begin{tabular}{lcc}
\hline Type of fistula & Number & Percentage \\
\hline Vesico-vaginal & 27 & $96.43 \%$ \\
Utero-vaginal & 01 & $3.57 \%$ \\
\hline
\end{tabular}

Table III

Aetiological pattern of fistula.

\begin{tabular}{lcc}
\hline Character & Number & Percentage \\
\hline Post-hysterectomy & 20 & $71.42 \%$ \\
Birth trauma & 06 & $21.42 \%$ \\
Post caesarean section & 02 & $07.14 \%$ \\
\hline
\end{tabular}


The mean operative time was 1.3 hours with range of 45 minute to 1.8 hours while the mean hospital stay was 6.5 days ranging from 5 to 8 days. Of the 28 fistulas $27(96.43 \%)$ were VVF and $1(3.57 \%)$ was UVF. From the aetiological point of view, out of 28 cases 20 $(71.42 \%)$ were post-hysterectomy complication, 6 $(21.42 \%)$ cases resulted from birth trauma and 2 $(7.14 \%)$ cases were post caesarean complication. Trans-abdominal route was used for operation in 22 $(78.56 \%)$ cases while $6(21.42 \%)$ cases were operated through trans-vaginal route. Of the 28 cases of urogenital fistula repaired in this series, $25(89.29 \%)$ cases were fully cured and 3 cases $(10.71 \%)$ experienced recurrence.

\section{Discussion}

The mean age of patients in the present series was 35.37 years. In most of the series where obstetric VVF contributes major proportion of the patients most patients are around 20 years of age[2,6]. As the majority of the patients in the present series are post hysterectomy $(71.42 \%)$ in origin the mean age is higher than that of the patients having VVF obstetric in origin.

The lowest age of the patient recorded in this series was 17 years and the patient was a primipara. The other three patients who developed fistula at their first confinement were below 18 years of age when the fistula occurred. The studies of Ibrahim et $\mathrm{al}^{1}$, Kelly and Kwast $^{3}$ and Tahzib ${ }^{4}$ showed the incidence of primiparous developing VVF tobe $81 \%, 62.7 \%$ and $52 \%$ respectively. A substantial number of cases of these series were below 16 and 18 years of age. In the present series incidence of primiparous developing VVF developed from child birth is $66.66 \%$ though thetotal number (6) of obstetric fistula is small. Females who become pregnant before they attain full maturity are prone to develop fistula because their birth canals are not adequately developed for the safe and easy passage of foetus ${ }^{5}$. Societies where females are married off at an earlier age face the higher incidence obstetric VVF. So the marital age of the female is an important determinant of development of obstetric VVF and other child birth injuries in a particular society and the early marrying off of the female child is determined by many factors like poverty, education, health awareness among mass population, religion, state demographic policy, presence or absence of discriminatory outlook towards female children etc. Poverty is a natural association of malnutrition which further retards the maturity.
In the present series, the incidenceof fistula following abdominal hysterectomy, prolonged labour and caesarean section was $71.42 \%, 21.42 \%$ and $7.14 \%$ respectively. Fistula from other causes such radiation, trauma, abortion and other pelvic surgery were lacking in the present series. In developed countries $90 \%$ fistulae are caused by gynaecological procedures ${ }^{5}$ and obstetric fistulae are becoming nonexistent.In our country the aetiology of genitourinary fistulae was mostly related to birth injury up to the eighties of the past century because of the lack of emergency obstetric care throughout the country as well as the lack of good communication. The study of Begum A conducted in Dhaka Medical College and Mymenshing Medical College during the period January, 1987 to December,1988 over 100 women with VVF showed $100 \%$ cases were of obstetric origin[6]. This major shift in the of aetiology of female urogenital fistulae from birth injury to post-surgical one reflects the availability of emergency obstetric care to the major segment of our population. In the study of Kochakarn $W$ and PummanguraW ${ }^{7}$ the aetiology of VVF has been reported $62.2 \%, 22.2 \%, 8.8 \%$ and $6.6 \%$ respectively fromlaparoscopic hysterectomy, abdominal hysterectomy, trans-vaginal hysterectomy and radical hysterectomy for malignant disease. Laparoscopic hysterectomy dominates in the aetiology of VVF where laparoscopy has been taken up by the gynaecologicalsurgeons but in thepresent series the laparoscopic hysterectomy has contributed in $14.28 \%$ cases indicating that laparoscopy has not been accepted by majority of the gynaecological surgeons in our country.

The time lapse between the onset fistula and repair has a wide range in the series beginning from 4 months to 29 year. The senior most patient of this series developed fistula during her last confinement and remained untreated for long 29 year until her last child whose birth was cursed with the development of VVF took her to the present author. Another patient of this series developed VVF duringher first confinement and remained untreated for about 23 years and bore another 2 children. This prolonged delay in the treatment of these two patients was mainly due to poverty but lack of fistula care facility around the patient's abode contributed too.In the present series repair was deferredfor at least 4 months after the onset of VVFto allowoedema and inflammation to subside. It has been shown that the infection of the vaginal cuff or pelvis after abdominal hysterectomy require prolonged 
antibiotic therapy before attempt at repair[8]. Delay is more important for the patients from poverty stricken societies where malnutrition and its sequels are common associations posing negative prognostic factor for healing.Repair must be deferred in cases resulting from radiation and those associated with extensive tissue loss, de-vascularization andinfection. Deferred surgery allows time for the tissue to recover and infection to be cleared off[9]. However, there are serieses ${ }^{10,11}$ albeit with small number of cases ( 7 and 11 cases respectively) reporting early repair ranging from 1-3 months after the diagnosis of fistula and their success rate ranged from 86 to $100 \%$. They are of the opinion that once acute inflammation has subsided there is no benefit in delaying the surgery.Rather early surgery offers a respite from the devastating impact on the quality of life for the patient[12]. However one should be very cautious in selecting cases for early repair so that thesurgical outcomeis notcompromised.

In this series $78.56 \%$ (22 cases) fistulae have been repaired through abdominal route and the rest, $21.42 \%$ (6 cases), trans-vaginal route. Cases resulting from abdominal hysterectomy have been considered best suitedto trans-abdominal routebecause of the location of the fistula at the vaginal vault and also its proximity to the ureteric orifices. The indications for transabdominal route include high fistula that are inadequately exposed, ureterovaginal fistula requiring ureteral re-implantation, vaginal stenosis or adverse musculoskeletal conditions, supra-trigonal fistula, small capacity or poorly compliant bladder requiring bladder augmentation[12]. The main advantage of this approach is that the omentum having rich vascular supply and lymphatic drainage can readily be mobilized as an inter-positional flap[12]. This flap provides the suture lines with a well vascularized graft and mechanism for absorption of debris increasing the chance of success of the repair[13]. We approached the low fistula through the trans-vaginal route which avoids laparotomy and splitting of the bladder. It has the advantage of less morbidly, blood loss, and postoperative bladder irritability. It is also associated with less postoperative pain, can be done even in outpatient setting and offers success rate as good as that of abdominal approach.

As done by most surgeons[12], success in this series has been defined asthe respite from urinary leakage at the time of discharge from hospital.Success rate in the present series is $89.29 \%$. Kelly[14] reported success rate of $58 \%$ to $90 \%$ and Cron[15] reported
$85 \%$ success rate. Success rate of female genitourinary fistula surgery depends on many factors including degree fibrosis surrounding fistula site, site and size of fistula, number of previous attempt and overall health of the patient.Among these factors fibrosis at the fistula site is the most importantdeterminant of surgical outcome including the healing, bladder capacity and future behaviour of the urinary bladder. A small fibrotic bladder becomes noncompliant and leads to the frequency with or without urge despite respite from leakage of urine. Some patients may even develop urge incontinence; a newer sort of malady.Post-surgical incontinence is more common after repair urethrovaginal fistula and fistula involving bladder neck[16]. In the present series no patient complained of frequency or incontinence which might be explained by the absence of fistula involving the urethra and most fistulae are iatrogenic in origin which is associated with less fibrosis around the fistula than those caused by prolonged obstructed labour.

\section{Conclusion}

Aetiological pattern of female urogenital fistula of a particular country in fact reflects the status of the health care service, maternal care service in particular as well as many other social and economic parameters of that country. Fistula resulting from birthtrauma is prevalent in countries where maternal care service is far from satisfactory; females are married off early before attaining physical maturity for child bearing and primitive communication. Lack of health awareness preventing from seeking medical advice in time, poor economic affordability to pay for medical service and appropriate nutrition also play parts in developing obstetric urogenital fistula.Female urogenital fistula due to birth trauma has become nonexistent incountries where all these adversaries have been eliminated. In our country birth trauma was the sole cause of female urogenital fistula up to 1980's, thereafter the scenario began to change. Discernible development has been made in different sectors including the health care system as a result the aetiological dominance of female urogenital fistula has been shifted from birth trauma to iatrogenic one approaching to that of developed country. In fact aetiological pattern of female urogenital fistula reflects the status ofmanysectors of a country including health care, education, and communication and over all social and human development.

\section{References}

1. WassLL,Karshim JA, Kirschner C, Arrowsmith $S D$. The obstetric vesicovaginal fistula: Characteristics of 899 patients from Jos, Nigeria. Am J ObstetGynecol 2004;190(4):1011-9. 
2. Khan RM, Reza N,Zehanzaib M, Sultana R. Vesicovaginal fistula: An experience of 30 cases at Ayub teaching hospital,Abbottabad.JAyub Med CollAbbottad 2005;17(3).

3. Kelly J. Fistulae of obstetric origin. Midwifery 1991;7(2):71-3.

4. Tahbiz F. Epidemiological determinants ofvesicovaginal fistulas. $\mathrm{Br} \mathrm{J}$ ObstetGynecol 1983;9090(5):387-91.

5. Tancer ML. Observation on prevention and management of vesicovaginal fistula after total hysterectomy. Surg GynaecolOnstet 1992;175:501-6.

6. Begum A. Vesico-vaginal fistula: surgical management of 100 cases. Journal of Bangladesh College of Physicians and Surgeons 1989; 6(2): 29-32.

7. Kochakarn $W$ and Pummangura W. A new dimension in vesicovaginal fistula management: An 8-year experience at Ramathibodi Hospital. Asian jounal of Surgery 2007;30:267-279.

8. BlaivasJG,HeritzDM,Romanzi LJ. Early versus late repair of vesicovaginal fistulas: vaginal and abdominal approaches. The journal of urology 1995;153:1110-1113.
9. Smith $\mathrm{GL}$ and Williams $\mathrm{G}$. Vesicovatginal fistula. BJU International 1999;83:564-570.

10. PerskyL,Herman G, Fuerrier K. Nondelay in vesicovaginal repair.Urology.1979;13:2735.[PubMed:11336734]

11. Cruikshank SH. Early Closure of posthystrectomyVesicovaginal fistulas. South Med J. 1998;81:1525-8.[PubMed:442344]

12. CreangaAA,Genadry RR. Obstetric fistulas: $A$ clinical review. International Journal of Gynaecology and Obstetrics 2207;99: s40-s46.

13. Turner-Warwick R. The use of omental pedicle graft in urinary tract reconstruction. J Urol 1976;116:341-7.[ PubMed: 785032].

14. Kelly J.Fistulae of obstetric origin. Midwifery 1991;7(2): 71-73.

15. Cron J. Lesson from the developing world: obstructed labour and vesico-vaginal fistula. MedGenMed 2003;5(3):24.

16. arrowsmith S, WallEC. Obstructed labour injury complex: obstetric fistula formation and the multifaceted morbidity of maternal birth trauma in the developing world. ObstetGynecolSurv 1996; 51(9):568-74. 